\title{
Health-related quality of life as a predictor of mortality in heterogeneous samples of older adults
}

\section{Liira, Helena}

2018-04

Liira , H, Mavaddat , N , Eineluoto , M , Kautiainen , H, Strandberg , T , Suominen , M , Laakkonen , M-L , Eloniemi-Sulkava , U , Sintonen , H \& Pitkälä , K 2018 , ' Health-related quality of life as a predictor of mortality in heterogeneous samples of older adults ' , European Geriatric Medicine , vol. 9 , no. 2 , pp. 227-234 . https://doi.org/10.1007/s41999-018-0029-3

http://hdl.handle.net/10138/311608

https://doi.org/10.1007/s41999-018-0029-3

acceptedVersion

Downloaded from Helda, University of Helsinki institutional repository.

This is an electronic reprint of the original article.

This reprint may differ from the original in pagination and typographic detail.

Please cite the original version. 
Health-related quality of life as a predictor of mortality in heterogeneous samples of older adults

Helena Liira1,2

Nahal Mavaddat2

Maija Eineluoto1

Hannu Kautiainen1

Timo Strandberg3,4

Merja Suominen1

Marja-Liisa Laakkonen1

Ulla Eloniemi-Sulkava5

Harri Sintonen6

Kaisu Pitkälä1

1 University of Helsinki, Department of General Practice, and Helsinki University Hospital, Unit of Primary Health Care

2 General Practice, School of Primary, Aboriginal and Rural Health Care, University of Western Australia

3 Geriatric Clinic, Department of Medicine, University of Helsinki, Helsinki, Finland, 4 Institute of Health Sciences/ Geriatrics, University of Oulu, and Oulu University Hospital, Oulu, Finland 5 Centre for Continuing Education, University of Helsinki

6 Department of Public Health, University of Helsinki 
Corresponding author:

Helena Liira

helena.liira@helsinki.fi

Word count: 2,498

Key words: health-related quality of life, older adults, mortality

Key points:

- Health-related quality of life (HRQoL) was measured in eight cohorts of older adults with multimorbidities and various functional, cognitive, psychological or social disabilities.

- $15 \mathrm{D}$, a generic HRQoL predicted independently and significantly the 2-year survival in the total sample.

- However, 15D did not predict mortality in samples of spousal caregivers and lonely older adults.

- In older populations suffering from psychological and social impairments such as caregiver burden or loneliness HRQoL may not be the appropriate tool to detect those at risk. 


\section{Abstract}

\section{Background:}

Health-related quality of life (HRQoL) is associated with survival in older people with multimorbidities and disabilities. However, older people differ in their characteristics, and less is known about whether HRQoL predicts survival in heterogeneous older population samples differing in their functional, cognitive, psychological or social disabilities. The aim of this study was to explore HRQoL in heterogeneous samples of older men and women, and to explore its prognostic significance for mortality.

\section{Methods:}

We analysed combined individual patient data from eight heterogeneous study samples all of which were assessed with the same methods. We used 15D, a generic, comprehensive instrument for measuring HRQoL, which provides a single index in addition to a profile. Two-year mortality was retrieved from central registers.

\section{Results:}

Health-related quality of life measurements with 15D were available for 3153 older adults. The mean HRQoL was highest among older businessmen (0.878) and lowest among nursing home residents (0.601).15D predicted independently and significantly the 2-year survival in the total sample (Hazard Ratio (HR)/ SD 0.44, 95\% CI 0.40 to 0.48)). However, 15D did not predict mortality in samples of spousal caregivers, lonely older adults and cardiovascular patients.

Conclusions: 15D captures health and disability factors associated with prognosis whereas in older populations suffering from psychological and social impairments such as caregiver burden or loneliness HRQoL may not reflect their health risks. 


\section{Introduction}

As functional impairments and losses concur with ageing, health-related quality of life (HRQoL) also declines as people age. On the other hand, ageing entails a number of positive dimensions and coping mechanisms that may improve overall quality of life $(\mathrm{Q} o \mathrm{~L})(1,2)$. The relationship between HRQoL and aging is therefore complex.

There are several measurement scales available to measure HRQoL in older adults, with various emphases on different dimensions of health (3). Both disease specific and generic measures exist, and based on the underlying concept of health and well-being, they may include various dimensions such as emotions, cognitive function, economic status, and intelligence. However, in the heterogenous populations of older adults and it is still uncertain whether established measures address dimensions of HRQoL meaningful to older adults (2).

Heterogeneity in health including physical, mental, cognitive and social functioning increases between individuals as they age. Older populations carry specific risks and burdens that may significantly affect their QoL and survival $(4,5)$. Nevertheless, older people often evaluate their QoL as being better than external evaluators do (2). In addition to diseases, disabilities and health-related factors, psychosocial, socioeconomic, environmental, and spiritual dimensions may be equally important for the QoL of older adults and thus may modify QoL measures (6). QoL in old age is often dependent amongst other factors on coping ability, attitudes, social activity and networks and life events, especially losses. Thus, the predictive value of HRQoL on health and survival may be less certain in older populations. 
HRQoL has been shown to predict mortality in healthy populations (7), among seniors attending primary care clinics (8) and in a mixed population of older adults (9). However, this has not been extended to other older people with cognitive deficits or in those with unique psychosocial circumstances such as lonely older people and caregivers.

To better understand the importance of HRQoL in older adults, we assessed HRQoL and its prognostic value in eight prospective samples of older adults, each with different proportions of genders, varying ages and comorbidity features, as well as having different levels of physical, cognitive, psychological, and social functioning. Our aim was to compare HRQoL in these diverse groups and to determine whether HRQoL predicts mortality in older adults - both men and women - in various life circumstances.

\section{Design and Methods}

\subsection{Study population}

Eight samples of older adults were studied for the association between HRQoL and mortality. The samples and the clinical processes in each study have been described in detail previously (1017). The six randomised controlled trials (RCT) were originally designed to solve various clinical or psychosocial problems related to older age. In addition, the set of studies included two prospective cohort studies. The Helsinki Businessmen study (HBS) is an on-going cohort study following Helsinki based executives born between 1919 and $1934(14,17)$. The second cohort study is a random population sample, which was retrieved from the Finnish Population Register 
in 2004 to serve as a comparison sample for the DEBATE study (10). The specific characteristics of the studies are presented in Table 1.

Mortality data up to two years were retrieved from the Finnish Population Information System (Population Register Centre, Helsinki, Finland), which keeps a register of all Finnish citizens; thus, our determination of the vital status is virtually $100 \%$ complete.

\subsection{Study prooedures}

The same study group carried out the six RCTs and the two cohort studies; hence, similar study procedures were applied in all these studies. The information was gathered during a baseline visit, which generally lasted about one hour and included interviews with the participant or caregiver or both. Researchers collected demographic data, diagnoses, and current medications. Diagnoses and medications were confirmed from the medical records.

We assessed health-related quality of life of patients using the 15D instrument (18). The 15D is a generic, comprehensive (15-dimensional), instrument for measuring HRQoL among adults. The dimensions of the 15D are mobility, vision, hearing, breathing, sleeping, eating, speech, excretion, usual activities, mental function, discomfort and symptoms, depression, distress, vitality, and sexual activity. It combines the advantages of a profile and a preference-based, single index measure. A set of utility or preference weights is used to generate the 15D score (single index number). The index varies between 0 (poorest HRQoL) and 1 (excellent HRQoL). The validity of 15D has been assessed in several populations. In older populations including dementia patients it shows discriminant, criterion and prognostic validity (19). Recently, it was studied in patients 
with chronic pain, and compared with EQ-5D. Both instruments were valid and 15D somewhat more sensitive. (3) Similarly, the validity was confirmed in a comparison with several other HRQoL instruments in patients with rheumatoid arthritis (20). Usually the subject concerned fills in the survey, but it may also be completed through an interview with the subject or their proxy. A difference of 0.015 in the 15D score between patient groups is considered minimally clinically important (21).

A number of other measures were also included to characterise the samples. These were the Charlson Comorbidity Index, which was calculated to assess the severity and prognostic value of the participants' burden of diseases (22), the Mini Mental State Examination (MMSE) (23) to assess cognition (in all samples except the population cohort), dementia diagnoses, self-rated health, physical functioning according to "personal care" in Clinical Dementia Rating (24), and life satisfaction ("Are you satisfied with life?"(yes/ no).

\subsection{Ethical approval}

Local ethics committees approved the study protocols of each individual study. Written informed consent was obtained from all participants or, in the event of cognitive impairment, from the participant's closest proxy prior to study participation.

\subsection{Statistical analyses}

In the statistical analyses, all participants aged 64 or less were excluded from the samples to focus solely on older individuals. To prevent individual subjects from participating twice and having samples dependent on each other, in cases where patients had been recruited to more 
than one of our samples, they were excluded from the larger sample. Statistical significance between samples was evaluated by analysis of variance (ANOVA), the Kruskall-Wallis test or chisquare test. The normality of variables was evaluated by the Shapiro-Wilk W test. Correlation coefficients were calculated by the Spearman method.

For each sample, the time-to-event analysis was based on the product limit (Kaplan-Meier method) estimate of the cumulative 2-year 'mortality' function. The Log-rank method was used to identify mortality differences. The Cox proportional hazards model was used to estimate the predictive value of baseline HRQoL for age and gender adjusted 2-year mortality for each sample. We also used hazard ratios to estimate how 2-year mortality increases for per 1-SD increase in 15D. Using for per 1-SD allows us to standardize varying mortality in these heterogeneous samples and to make them comparable. The proportional hazards assumption was tested graphically and by use of a statistical test based on the distribution of the Schoenfeld residuals. There was no evidence of violation of the proportional-hazards assumption in covariate-specific and global tests. We also combined comparable individual patient data from the original studies: baseline findings from seven trials and two prospective cohort studies, to give an overall hazard ratio for mortality at 2 years. The caregivers' sample was obtained from combining two dementia trials $(12,14)$.

\section{Results}

\subsection{Characteristics of the subjects}

The baseline characteristics for the eight samples are presented in Table 1. The mean age of the subjects in the samples varied from 75 to 85 years. In six studies, approximately two-thirds of the 
subjects were women. The two exceptions were the HBS, which only included men, and the 'Dementia' study, in which only 35\% of subjects were women due to the fact that home-dwelling male patients with dementia are often cared for by their wives.

Whereas nearly all nursing home residents were dependent in their ADLs, and two out of three patients in the 'Delirium' trial and in the 'Dementia' studies needed assistance, only very low proportions in the other samples needed help with their personal care. All those in the 'Dementia' sample, $95 \%$ in the nursing home sample and $44 \%$ in the 'Delirium' sample suffered from dementia, while other samples had very low numbers of dementia patients. The MMSE points were lowest among nursing home patients (mean 9.4), followed by patients with delirium (14.4) and home-dwelling patients with dementia (20.1) (Table 2).

The Charlson comorbidity index was highest in the DEBATE study (mean 3.7), followed by nursing home residents (2.7) and delirium patients (2.6). The same samples had also the highest mean number of drugs (Table 2). On the other hand, the HBS men and the spousal caregivers had the lowest number of drugs and comorbidities. HBS participants had the highest proportion (96\%) of those rating their health as good, followed by those in the population sample (88\%), whereas only $49 \%$ of participants in the 'Delirium' trial rated their health as good.

Life satisfaction was highest in the population sample (94\%), among HBS men (93\%) and among the DEBATE participants (91\%). The lowest proportions of those satisfied with their lives were found among spousal caregivers (74\%) and in the participants from the 'Loneliness' study (82\%).

3.2 Health-related quality of life and the sample characteristics 
Mean HRQoL as measured by the 15D in the total sample was 0.792 (SD 0.14). HRQoL was highest in the HBS study at 0.878 (SD 0.099). Generally, samples with the highest HRQoL by 15D measurements were also those with higher life satisfaction $(r=0.22 ; \mathrm{p}<0.001)$ and fewer comorbidities $(r=0.38 ; p<0.001)$. Although fewer spousal caregivers were satisfied with life, their HRQoL was the second highest of all the samples (mean 0.844, SD 0.100). In the population sample, the mean 15D was also high (0.796, SD 0.132) as was HRQoL in the DEBATE study (0.794, SD 0.105), in patients with dementia (0.776, SD 0.117), and in the 'Loneliness' group (0.777, SD 0.117).

The lowest HRQoL on the other hand was observed among nursing home residents (mean 15D 0.601, SD 0.118). Moreover, the participants from the 'Delirium' trial also had low mean 15D index scores (0.731, SD 0.115).

3.3 Health-related quality of life and mortality

During the two-year follow-up, a total of 386 deaths occurred, 231 in women and 155 in men. Mortality was highest among nursing home residents ( $42 \% / 2$ years) and among delirium patients (32\%/ 2 years), and lowest among HBS men (4.2\%) and spousal caregivers (4.3\%) (see Figure 1, Panel A). There was a strong age-adjusted association between decreasing HRQoL and increasing mortality in both men and women (Figure 2, Panel B).

HRQoL as measured by 15D significantly predicted the 2-year survival in the total sample of participants of older age (Figure 3, Panel B). One SD (0.14) higher in the 15D index score from the weighted mean halved the mortality during the 2-year follow-up (HR 0.44, 95\% CI 0.40 to 0.44 , 
$\mathrm{p}<0.001$; adjusted by age and sex). While in all other samples the lower 15D predicted mortality, in the samples for spousal caregivers (HR 1.06, 95\% CI 0.43 to 2.63, $p=0.90$, adjusted for age and sex), DEBATE participants (HR 0.68, 95\% CI 0.42 to 1.09) and older adults in the 'Loneliness' study (HR 0.94, 95\% CI 0.47 to 1.87, $\mathrm{p}=0.85$; adjusted for age and sex), HRQoL was not associated with mortality. Adjusting for the Charlson Comorbidity index did not alter the significant relationship between the 15D and mortality overall and in any subpopulation.

\section{Discussion}

Poor HRQoL as measured with the 15D predicted all-cause mortality during the 2-year follow-up in the combined sample of more than 3000 older individuals. The association was independent of age, gender and also comorbidities. As well, HRQoL of life was independently associated with mortality at two years in most samples of older people including those with dementia, in nursing homes and with delirium. According to our findings then, the 15D captures well health and disability factors associated with poorer prognosis in clinical samples of older adults.

However, there were three samples where HRQoL did not predict mortality: the studies on spousal caregivers, the 'Loneliness' study, and the DEBATE study targeting older adults with considerable cardiovascular diseases. While this might be due to low statistical power, these populations also differ from others in certain aspects that might affect the relationship between HRQoL and mortality.

A lack of an association between the 15D and mortality at 2 years in our study was seen particularly in older populations where there were particular psychosocial impairments, i.e. in 
the loneliness and in the caregiver samples where participants suffered from burden and strain of caregiving. Both situations are known to be associated with deteriorated health and mortality. The characteristics of both samples included independence in daily functioning and fairly low number of comorbidities. Although physically healthy a larger proportion of the individuals in these samples showed low satisfaction of life than in other samples. Along with these two samples the DEBATE sample was also very independent in their ADL activities. At the same time they suffered from serious cardiovascular diseases exposing them to complications and mortality. Thus, HRQoL emphasizing functioning may not capture the health risks of this sample.

Previous studies have shown that caregivers of people with dementia suffer from both mental and physical health problems (24). It has been suggested that caregivers experiencing strain have significantly elevated mortality risk even after adjustment for age, gender and comorbidities (25). Although the HRQoL measures often assess an individual's depression, anxiety and physical capabilities, they may not capture the distress and burden caused as a result of caring for someone with a significant health condition. Monitoring caregivers' non-traditional health risks-such as burden, stress, and strain - may better capture the relevant health risks in this group of older adults. Findings in the 'Loneliness' group of our study also deviated from that of the other samples in that the 15D again did not predict two-year mortality in this group. Compared to the population sample, these participants had rather poor self-rated health (64\% vs. $88 \%$ ) and lower satisfaction with life ( $82 \%$ vs. $94 \%$ ), although showing similar quality of life to the other groups as measured by 15D. Social and psychological pressures such as loss of close ones, disabilities, and lack of meaningful activities reduce life satisfaction among lonely $(26,27)$. There is indeed a growing body of evidence suggesting that loneliness is independently 
associated with morbidity, cognitive decline and mortality $(28,29)$. However, the HRQoL measures may not to be able to detect such health risks adequately. Understanding and measuring those factors that impact the health of lonely people requires further study and additional measurement scales.

The strengths of our study include the fact that our samples were prospective and carefully studied using well-chosen clinical assessment methods. They represent the wide variety of heterogenities in older populations. The parallel samples give us an opportunity to explore different aspects of quality of life and other participant-important measures of older age. A possible weakness of the study is that the samples had different inclusion and exclusion criteria and we cannot claim the material represents the whole population. Another possible threat to the validity of our study is that we included both the intervention and control arms of the randomised controlled trials. Nevertheless, the interventions did not have any effect on our outcome measure of mortality in the 2-year follow-up. Therefore, we believe that the generalisability of our results remains good in populations comparable to Finnish older adults.

\section{Conclusions}

In conclusion our analysis revealed that overall, the 15D generic quality of life measure predicts

well 2-year mortality in clinical samples of older adults independent of disease burden. Not only is the 15D therefore a valid tool for measuring HRQoL in older adults, it also is a valuable instrument to capture health and disability associated with poor prognosis in most older people's samples. However, in older populations suffering from psychological and social impairments, such as those with caregiver burden or loneliness, the HRQoL 15D measure may not be the best 
tool to detect those at risk, and exploration of additional emotional and social well-being measures is therefore warranted.

\section{Acknowledgements}

This study was supported by University of Helsinki and University of Western Australia.

\section{Conflicts of interest}

HS is the developer of the 15D instrument and obtains royalties from the electronic versions of the instrument. Otherwise, the authors declare no conflict of interest that could be perceived as prejudicing the impartiality of the research reported. 


\section{References}

1. Henchoz Y, Meylan L, Goy R, Guessous I, Bula C, Demont M, et al. Domains of importance to the quality of life of older people from two Swiss regions. Age Ageing. 2015;44(6):979-85.

2. $\quad$ Frytak J. Assessment of quality of life in older adults. In: Kane RL, Kane RA, editors. Assessing older persons Measures, meaning, and practical applications. New York: Oxford University Press; 2000. p. 200-36.

3. Vartiainen P, Mäntyselkä P, Heiskanen T, Hagelberg N, Mustola S, Forssell H, Kautiainen H, Kalso E. Validation of EQ-5D and 15D in the assessment of health-related quality of life in chronic pain. Pain. 2017 Aug;158(8):1577-1585.

4. Brodaty H, Green A, Koschera A. Meta-analysis of psychosocial interventions for caregivers of people with dementia.J Am Geriatr Soc. 2003;51(5):657-64.

5. Pitkala KH, Laakkonen ML, Strandberg TE, Tilvis RS. Positive life orientation as a predictor of 10-year outcome in an aged population. J Clin Epidemiol. 2004;57(4):409-14.

6. Atkins J, Naismith SL, Luscombe GM, Hickie IB. Psychological distress and quality of life in older persons: relative contributions of fixed and modifiable risk factors. BMC Psychiatry. 2013;13:249. 7. Kaplan MS, Berthelot JM, Feeny D, McFarland BH, Khan S, Orpana H. The predictive validity of health-related quality of life measures: mortality in a longitudinal population-based study. Qual Life Res. 2007;16(9):1539-46.

8. Dorr DA, Jones SS, Burns L, Donnelly SM, Brunker CP, Wilcox A, et al. Use of health-related, quality-of-life metrics to predict mortality and hospitalizations in community-dwelling seniors. J Am Geriatr Soc. 2006;54(4):667-73.

9. Brown DS, Thompson WW, Zack MM, Arnold SE, Barile JP. Associations between healthrelated quality of life and mortality in older adults. Prev Sci. 2015;16(1):21-30.

10. Strandberg TE, Pitkala K, Berglind S, Nieminen MS, Tilvis RS. Multifactorial cardiovascular disease prevention in patients aged 75 years and older: A randomized controlled trial: Drugs and Evidence Based Medicine in the Elderly (DEBATE) Study. Am Heart J. 2001;142(6):945-51.

11. Pitkala KH, Laurila JV, Strandberg TE, Tilvis RS. Multicomponent geriatric intervention for elderly inpatients with delirium: a randomized, controlled trial. J Gerontol A Biol Sci Med Sci. 2006;61(2):176-81.

12. Eloniemi-Sulkava U, Saarenheimo M, Laakkonen ML, Pietila M, Savikko N, Kautiainen H, et al. Family care as collaboration: effectiveness of a multicomponent support program for elderly couples with dementia. Randomized controlled intervention study.J Am Geriatr Soc. 2009;57(12):2200-8.

13. Pitkala KH, Routasalo P, Kautiainen H, Tilvis RS. Effects of psychosocial group rehabilitation on health, use of health care services, and mortality of older persons suffering from loneliness: a randomized, controlled trial.J Gerontol A Biol Sci Med Sci. 2009;64(7):792-800.

14. Sirola J, Pitkala KH, Tilvis RS, Miettinen TA, Strandberg TE. Definition of frailty in older men according to questionnaire data (RAND-36/ SF-36): The Helsinki Businessmen Study.J Nutr Health Aging. 2011;15(9):783-7.

15. Laakkonen ML, Pitkala K. Supporting people who care for adults with dementia. BMJ. 2013;347:f6691.

16. Jyvakorpi SK, Puranen T, Pitkala KH, Suominen MH. Nutritional treatment of aged individuals with Alzheimer disease living at home with their spouses: study protocol for a randomized controlled trial. Trials. 2012;13:66.

17. Strandberg TE, Salomaa V, Strandberg AY, Vanhanen H, Sarna S, Pitkala K, et al. Cohort Profile: The Helsinki Businessmen Study (HBS). Int J Epidemiol. 2016;45(4):1074-h. 
18. Sintonen $\mathrm{H}$. The 15D instrument of health-related quality of life: properties and applications. Ann Med. 2001;33(5):328-36.

19. Strandberg TE, Pitkälä K, Sintonen H, Huusko T, Kautiainen H, Tilvis R. Utility, discriminant and prognostic validity of health related quality-of-life measure 15D. In: Huusko T, Strandberg T, Pitkälä K (Eds): Can we measure quality-of-life among older people? (In Finnish). The Central Union for the Welfare of the Aged. Helsinki, Finland 2006.

20. $\quad$ Linde L, Sørensen J, Ostergaard M, Hørslev-Petersen K, Hetland ML. Health-related quality of life: validity, reliability, and responsiveness of SF-36, 15D, EQ-5D, RAQoL, and HAQ in patients with rheumatoid arthritis. J Rheumatol. 2008;35(8):1528-37.

21. Alanne S, Roine RP, Rasanen P, Vainiola T, Sintonen H. Estimating the minimum important change in the 15D scores. Qual Life Res. 2015;24(3):599-606.

22. Charlson ME, Pompei P, Ales KL, MacKenzie CR. A new method of classifying prognostic comorbidity in longitudinal studies: development and validation. J Chronic Dis. 1987;40(5):373-83.

23. Folstein MF, Folstein SE, McHugh PR. "Mini-mental state". A practical method for grading the cognitive state of patients for the clinician.J Psychiatr Res. 1975;12(3):189-98.

24. Hughes CP, Berg L, Danziger WL, Coben LA, Martin RL. A new clinical scale for the staging of dementia. Br J Psychiatry. 1982;140:566-72.

25. Crellin NE, Orrell M, McDermott O, Charlesworth G. Self-efficacy and health-related quality of life in family carers of people with dementia: a systematic review. Aging Ment Health. 2014;18(8):95469.

26. Schulz R, Beach SR. Caregiving as a risk factor for mortality: the Caregiver Health Effects Study.JAMA. 1999;282(23):2215-9.

27. Victor CR, Bowling A. A longitudinal analysis of loneliness among older people in Great Britain.J Psychol. 2012;146(3):313-31.

28. Goll JC, Charlesworth G, Scior K, Stott J. Barriers to social participation among lonely older adults: the influence of social fears and identity. PLoS One. 2015;10(2):e0116664.

29. Holt-Lunstad J, Smith TB, Layton JB. Social relationships and mortality risk: a meta-analytic review. PLoS Med. 2010;7(7):e1000316.

30. Boss L, Kang DH, Branson S. Loneliness and cognitive function in the older adult: a systematic review. Int Psychogeriatr. 2015;27(4):541-53. 


\section{Legend to Figure 1.}

Mortality in heterogeneous samples of older people and its relationship with health-related quality of life according to 15D (Sintonen 2001). Panel A: 2-year mortality among men and women in heterogeneous samples of older adults. Panel B: 15D score and 2-year mortality in men and women in the combined samples. Panel C: Hazard Ratios with 95\% confidence intervals for mortality per SD of the 15D scores in eight samples and in combined data of the studies. 
Figure 1. Panel A.

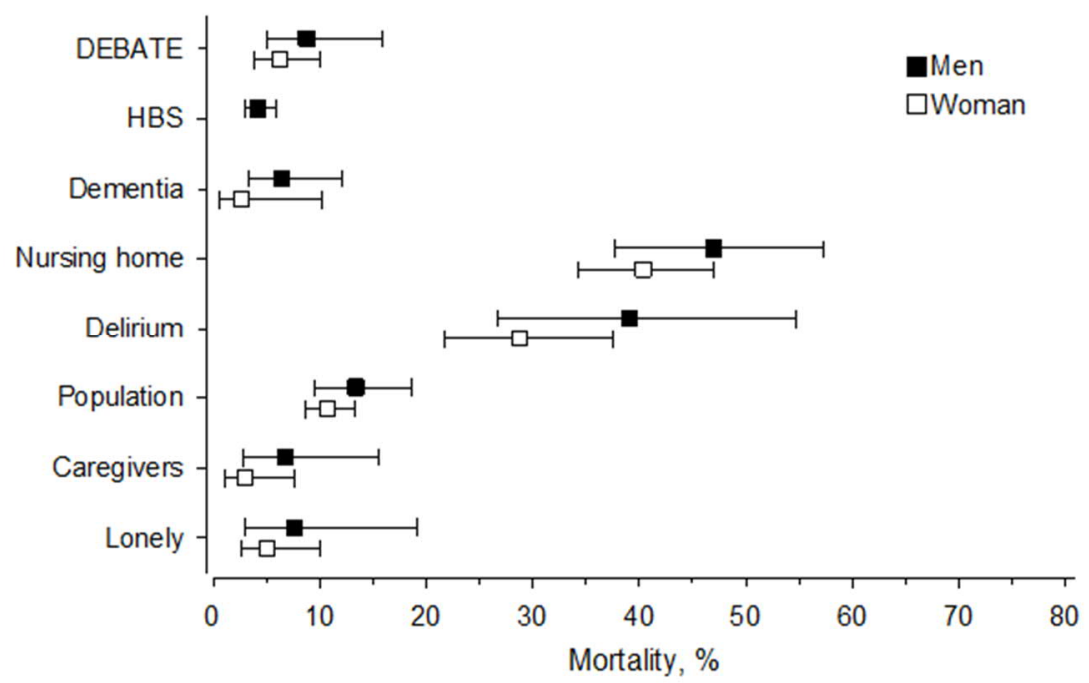

Panel B.

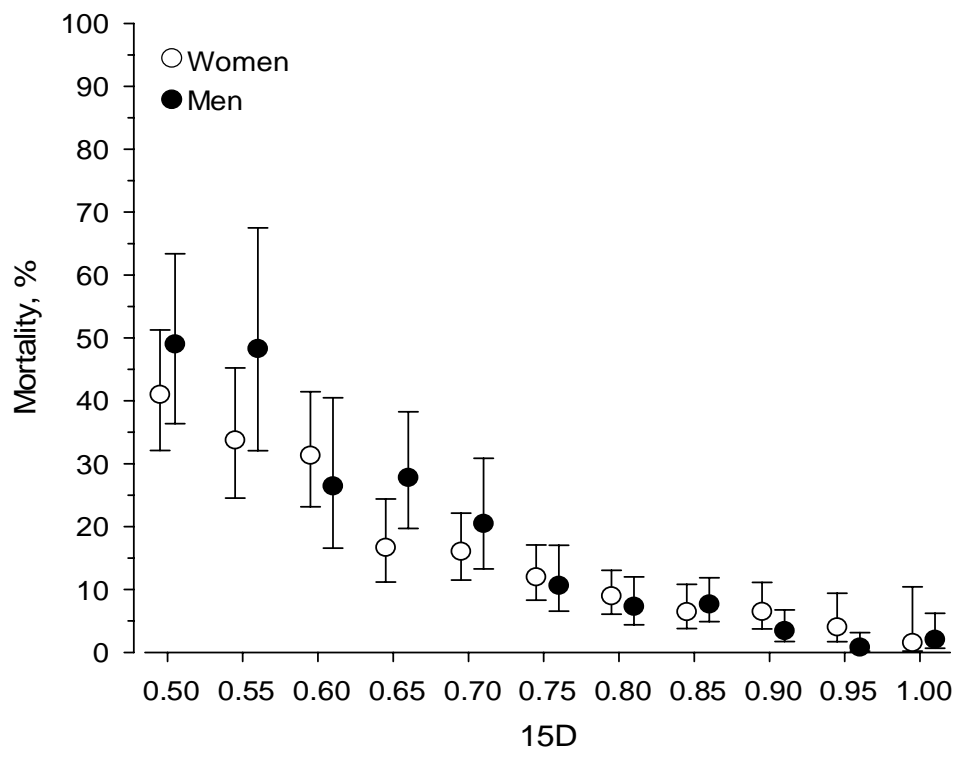

Panel C.

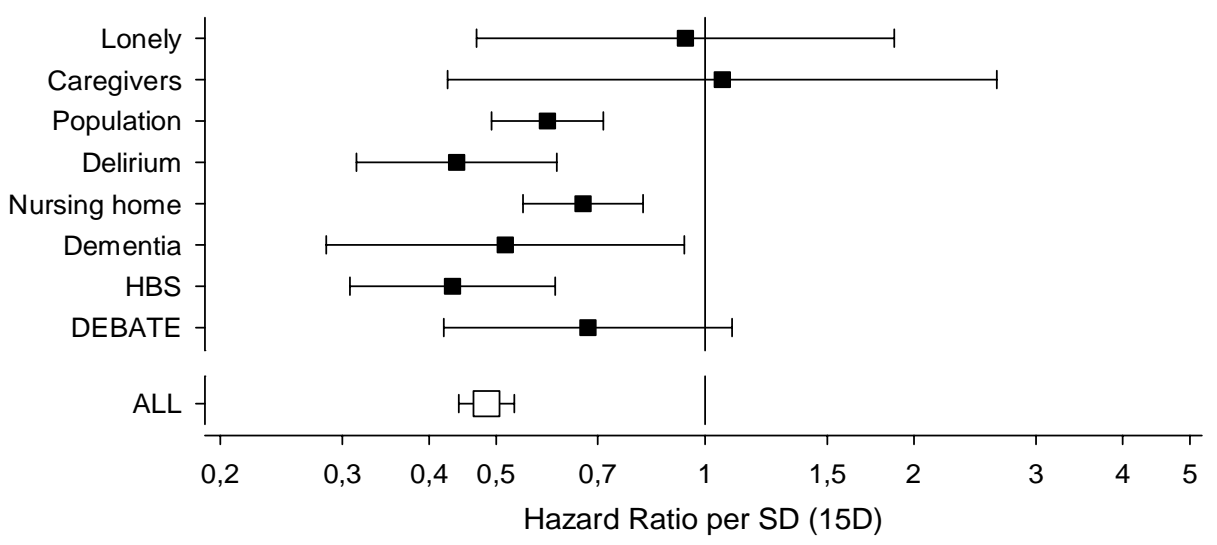


Table 1. Descriptions of original samples of older people in the study

\begin{tabular}{|c|c|c|c|c|c|c|c|c|}
\hline & $\begin{array}{l}\text { Home-dwelling } \\
\text { cardiovascular } \\
\text { patients } \\
(\mathrm{DEBATE}) 1 \\
(\mathrm{~N}=394)\end{array}$ & $\begin{array}{c}\text { Former } \\
\text { businessmen } \\
\\
(\mathrm{HBS})^{2} \\
(\mathrm{~N}=733)\end{array}$ & $\begin{array}{l}\text { Home dwelling } \\
\text { people with } \\
\text { dementia } \\
\text { ('Dementia') }{ }^{3} \\
(\mathrm{~N}=214)\end{array}$ & $\begin{array}{l}\text { Spousal caregivers of } \\
\text { people with dementia } \\
(\text { 'Spousal caregivers') } \\
(\mathrm{N}=209)\end{array}$ & $\begin{array}{l}\text { Hospitalized } \\
\text { patients with } \\
\text { delirium } \\
\text { ('Delirium') } \\
(\mathrm{N}=171)\end{array}$ & $\begin{array}{l}\text { Nursing home } \\
\text { residents } \\
\left(\begin{array}{c}\text { Nursing home') } \\
(\mathrm{N}=326)\end{array}\right.\end{array}$ & $\begin{array}{l}\text { Older people } \\
\text { suffering from } \\
\text { loneliness } \\
\left({ }^{\prime} \text { Loneliness' }\right)^{7} \\
(\mathrm{~N}=208)\end{array}$ & $\begin{array}{l}\text { Population } \\
\text { sample } \\
\text { "Population"8 } \\
(\mathrm{N}=901)\end{array}$ \\
\hline $\begin{array}{l}\text { Time and design } \\
\text { of the study }\end{array}$ & $\begin{array}{l}2000 \\
\text { RCT }^{9}\end{array}$ & $\begin{array}{c}2005 \\
\text { Prospective } \\
\text { cohort }\end{array}$ & $\begin{array}{c}2010 \& 2011 \\
\text { RCT }\end{array}$ & $\begin{array}{c}2004 \& 2010 \\
\text { RCT }\end{array}$ & $\begin{array}{l}2002 \\
\mathrm{RCT}\end{array}$ & $\begin{array}{l}2011 \\
\text { RCT }\end{array}$ & $\begin{array}{l}2004 \\
\text { RCT }\end{array}$ & $\begin{array}{c}2004 \\
\text { Postal survey } \\
\text { with follow-up } \\
\text { for mortality }\end{array}$ \\
\hline $\begin{array}{l}\text { Inclusion } \\
\text { criteria }\end{array}$ & $\begin{array}{l}\text { Independently } \\
\text { living older } \\
\text { people with } \\
\text { confirmed } \\
\text { atherosclerotic } \\
\text { disease }\end{array}$ & $\begin{array}{c}\text { Male business } \\
\text { executives born } \\
\text { 1919-1934 and } \\
\text { followed up } \\
\text { from 1970s for } \\
\text { their } \\
\text { cardiovascular } \\
\text { risk factors } \\
\end{array}$ & $\begin{array}{l}\text { Home-dwelling } \\
\text { person with } \\
\text { confirmed } \\
\text { diagnosis of } \\
\text { dementia and living } \\
\text { with a spousal } \\
\text { caregiver. }\end{array}$ & $\begin{array}{l}\text { Spouses taking care of } \\
\text { partner with dementia } \\
\text { and living at home }\end{array}$ & $\begin{array}{l}\text { Patients } \\
\text { suffering from } \\
\text { delirium } \\
\text { according to } \\
\text { DSM IV and } \\
\text { admitted to } \\
\text { geriatric ward }\end{array}$ & $\begin{array}{l}\text { Nursing home } \\
\text { residents aged } 65 \\
\text { or more }\end{array}$ & $\begin{array}{l}\text { Home dwelling } \\
75 \text { years or } \\
\text { older suffering } \\
\text { from loneliness }\end{array}$ & $\begin{array}{c}\text { Random } \\
\text { population- } \\
\text { based sample } \\
\text { aged } 75-95 \\
\text { years }\end{array}$ \\
\hline $\begin{array}{l}\text { Exclusion } \\
\text { criteria }\end{array}$ & $\begin{array}{c}\text { Living } \\
\text { permanently in } \\
\text { institutional care, } \\
\text { bedbound }\end{array}$ & & $\begin{array}{l}\text { Severe disease with } \\
\text { a prognosis of less } \\
\text { than } 6 \text { months }\end{array}$ & $\begin{array}{l}\text { Estimated prognosis } \\
\text { less than } 12 \text { months } \\
\text { Hearing loss }\end{array}$ & $\begin{array}{l}\text { Estimated life } \\
\text { expectancy of } \\
\text { less than } 6 \\
\text { months }\end{array}$ & $\begin{array}{l}\text { Estimated life } \\
\text { expectancy less } \\
\text { than } 6 \text { months }\end{array}$ & $\begin{array}{c}\text { Moderate or } \\
\text { severe dementia }\end{array}$ & $\begin{array}{c}\text { Living } \\
\text { permanently } \\
\text { in institutional } \\
\text { care } \\
\end{array}$ \\
\hline Intervention & $\begin{array}{l}\text { Multifactorial } \\
\text { intervention } \\
\text { where } \\
\text { cardiovascular } \\
\text { treatments were } \\
\text { optimized by a } \\
\text { geriatrician }\end{array}$ & Not Applicable & $\begin{array}{l}2012 \text { study: } \\
\text { Support groups for } \\
\text { people with } \\
\text { dementia. } \\
2013 \text { study: } \\
\text { Tailored nutritional } \\
\text { guidance for } \\
\text { dementia families }\end{array}$ & $\begin{array}{c}2004 \text { study: case co- } \\
\text { ordinator for dementia } \\
\text { families. } \\
2013 \text { study: Tailored } \\
\text { nutritional guidance for } \\
\text { dementia families. }\end{array}$ & $\begin{array}{l}\text { Comprehensive } \\
\text { geriatric } \\
\text { assessment for } \\
\text { patients with } \\
\text { delirium. }\end{array}$ & $\begin{array}{l}\text { Training sessions } \\
\text { for nursing staff } \\
\text { to recognize } \\
\text { potentially } \\
\text { harmful } \\
\text { medications and } \\
\text { adverse drug } \\
\text { events }\end{array}$ & $\begin{array}{l}\text { Psychosocial } \\
\text { group } \\
\text { intervention } \\
\text { based on the } \\
\text { participants' } \\
\text { preferences }\end{array}$ & $\begin{array}{c}\text { Not } \\
\text { Applicable }\end{array}$ \\
\hline
\end{tabular}

${ }^{1}$ Strandberg et al. 2001; ${ }^{2}$ Strandberg et al. 2016; ${ }^{3}$ Laakkonen et al. 2012, Suominen et al. $2015 ;{ }^{4}$ Eloniemi-Sulkava et al. 2009, Suominen et al. 2015; ${ }^{5}$ Pitkala et al. 2006; ${ }^{6}$

Juola et al. 2014; ${ }^{7}$ Pitkala et al. $2009 ;{ }^{8}$ Population sample used for comparison sample of "DEBATE" study. ${ }^{9}$ RCT=randomised, controlled trial 
Table 2. Baseline characteristics for the eight samples of older people according to clinical variables

\begin{tabular}{|c|c|c|c|c|c|c|c|c|c|}
\hline & $\begin{array}{l}\text { DEBATE } \\
(\mathrm{N}=394)\end{array}$ & $\begin{array}{c}\text { HBS } \\
(\mathrm{N}=733)\end{array}$ & $\begin{array}{l}\text { 'Dementia' } \\
(\mathrm{N}=214)\end{array}$ & $\begin{array}{c}\text { 'Spousal } \\
\text { caregivers' } \\
(\mathrm{N}=209)\end{array}$ & $\begin{array}{l}\text { 'Delirium' } \\
(\mathrm{N}=171)\end{array}$ & $\begin{array}{l}\text { 'Nursing } \\
\text { home' } \\
(\mathrm{N}=326)\end{array}$ & $\begin{array}{l}\text { 'Loneliness' } \\
(\mathrm{N}=208)\end{array}$ & $\begin{array}{l}\text { Population } \\
\text { sample } \\
(\mathrm{N}=901)\end{array}$ & P-value ${ }^{8}$ \\
\hline Women, n (\%) & $257(65.2)$ & 0 & $75(35.0)$ & $135(64.6)$ & $125(73.1)$ & $228(69.9)$ & $156(75.0)$ & $677(75.1)$ & $<0.001$ \\
\hline Mean age, (SD) & $80(5)$ & $77(4)$ & $77(6)$ & $75(7)$ & $84(6)$ & $84(7)$ & $80(4)$ & $85(5)$ & $<0.001$ \\
\hline Living at home, n (\%) & $394(100)$ & $702(98.2)$ & $214(100)$ & $209(100)$ & $133(77.8)$ & $0(0)$ & $193(93.2)$ & $886(98.3)$ & $<0.001$ \\
\hline Low education ( $<8$ years), $\mathrm{n} \%$ & $182(46.2)$ & $0(0)$ & $65(31.3)$ & $53(26.2)$ & $87(51.2)$ & $213(67.2)$ & $101(49.8)$ & $436(49.7)$ & $<0.001$ \\
\hline $\begin{array}{l}\text { Dependent in ADL-activities } \\
\left(\mathrm{CDR}^{1} \text { 'personal care' >=1), } \mathrm{n}\right. \\
(\%)\end{array}$ & $0(0)$ & $50(8.6)$ & $134(61.2)$ & $2(0.9)$ & $114(65.9)$ & $318(98.8)$ & $0(0)$ & $54(5.9)$ & $<0.001$ \\
\hline Good self-rated health ${ }^{2}, \mathrm{n}(\%)$ & $265(68.5)$ & $702(95.8)$ & $158(76.3)$ & $157(79.7)$ & $75(48.7)$ & $189(72.1)$ & $128(63.7)$ & $774(88.5)$ & $<0.001$ \\
\hline Dementia $^{3}, \mathrm{n}(\%)$ & $2(0.5)$ & $26(3.6)$ & $214(100)$ & $0(0.0)$ & $76(44.4)$ & $309(95.1)$ & $6(2.9)$ & .. & $<0.001$ \\
\hline $\mathrm{MMSE}^{4}$, mean $(\mathrm{SD})$ & $26.3(2.6)$ & $28.4(2.0)$ & $20.1(5.2)$ & $27.5(2.2)$ & $14.4(5.3)$ & $9.4(8.1)$ & $27.0(2.5)$ & .. & $<0.001$ \\
\hline Charlson $^{5}$, mean (SD) & $3.7(1.8)$ & $1.2(1.4)$ & $2.2(1.4)$ & $1.2(1.4)$ & $2.5(1.9)$ & $2.6(1.7)$ & $2.0(1.6)$ & $1.4(1.6)$ & $<0.001$ \\
\hline Number of drugs, mean (SD) & $7.3(3.4)$ & $4.0(3.1)$ & $5.9(2.9)$ & $3.9(2.7)$ & $7.2(3.7)$ & $7.6(3.0)$ & $4.8(2.9)$ & $3.5(2.4)$ & $<0.001$ \\
\hline Satisfied with life, n (\%) & $353(91.0)$ & $673(93.1)$ & $114^{7}(87.0)$ & $78^{7}(73.6)$ & .. & $238(85.3)$ & $145(82.4)$ & $815(94.4)$ & $<0.001$ \\
\hline $15 \mathrm{D}^{6}$, mean $(\mathrm{SD})$ & $0.79(0.11)$ & $0.88(0.10)$ & $0.78(0.12)$ & $0.84(0.10)$ & $0.73(0.11)$ & $0.60(0.12)$ & $0.78(0.12)$ & $0.78(0.13)$ & $<0.001$ \\
\hline 2-year mortality, n (\%) & $28(7.1)$ & $31(4.2)$ & $11(5.1)$ & $9(4.3)$ & $54(31.6)$ & $138(42.3)$ & $12(5.6)$ & $103(11.4)$ & $<0.001$ \\
\hline
\end{tabular}

${ }^{1} \mathrm{CDR}=$ Clinical dementia rating (Hughes et al. 1982); ${ }^{2}$ Participants rated their health on the scale: very good/good/poor/very poor, with very good/good considered to good. ${ }^{3}$ Dementia diagnoses were either self-reported (HBS, Spousal caregivers, Older people suffering from loneliness, Population sample), retrieved from medical records

(Nursing home residents) or confirmed with thorough diagnostics (DEBATE, home-dwelling people with dementia, DELIRIUM); ${ }^{4}$ MMSE=Mini-mental State Examination (Folstein et al. 1975); ${ }^{5}$ Charlson comorbidity index (Charlson et al. 1987); ${ }^{6} 15 \mathrm{D}=$ generic measure for health-related quality-of-life (Sintonen 2001 ); ${ }^{7}$ Only participants from Eloniemi-Sulkava et al. 2009 study responded to this questions. ${ }^{8}$ The differences between the cohorts were tested by $\mathrm{X}^{2}$ test for categorical variables, Kruskall Wallis and ANOVA tests for continuous variables and Log Rank test for mortality. 